\title{
Effect of canola oil and natural antioxidant of basil on chemical and sensory properties of fresh cheese
}

\author{
Mihaela Ivanova ${ }^{1}$, Olga Teneva ${ }^{2}$, Mariya Dushkova ${ }^{1}$, \\ Radka Vlaseva ${ }^{1}$, Albena Stoyanova ${ }^{1}$
}

\author{
1 - University of Food Technologies, Plovdiv, Bulgaria \\ 2 - Plovdiv university "Paisii Hiledarski", Plovdiv, Bulgaria
}

Keywords:

Antioxidant

Canola

Oil

Cheese

Milk fat

Polyunsaturated

fatty acid

\section{Article history:}

Received 23.08.2019

Received in revised

form 16.12.2019

Accepted 30.06.2020

\section{Corresponding}

author:

Mihaela Ivanova

E-mail:

mihaela_18bg@abv.bg

DOI: $10.24263 / 2304-$

974X-2020-9-2-9

\section{Abstract}

Introduction. This research aims at determining the effect of canola oil and natural antioxidant of basil on chemical and sensory properties of fresh cheese.

Materials and methods. A fresh spreadable cheese was prepared by the use of fresh whole milk, canola oil and natural antioxidant of basil. The prepared cheese was analysed on fatty acid profile according to GC method of methyl esters, tocopherol content - according to HPLC method, phytosterol content - according to GC method, health lipid indices according to empirical calculations complying with the fatty acid profile of the product, sensory evaluation - according to 10-points hedonic scale.

Results and discussion. Canola oil was characterized by a high content of unsaturated fatty acid content above 93 g.100 $\mathrm{g}^{-1}$ of the total content and a very good ratio of omega$6 /$ omega-3 - 2/1. The total content of tocopherols in the lipid fraction was comparatively high $-315 \mathrm{mg} \cdot \mathrm{kg}^{-1}$. Canola oil contained significant amount of phytosterols $-0.7 \mathrm{~g} .100 \mathrm{~g}^{-1}$ with individual sterol composition $-\beta$-sitosterol $(54.7 \%)$ and campesterol $(35.3 \%)$ predominated in the sterol fraction.

The cheese with partial replacement of milk fat by canola oil was characterized by a reduced content of saturated fatty acids which have negative effects on the human health -35.18 g. $100 \mathrm{~g} \mathrm{~g}^{-1}$ compared to $68.33 \mathrm{~g} .100 \mathrm{~g}^{-1}$ in cheese produced by classical technology containing only milk fat. The product contained a large part of the short-chain fatty acids, typical for milk fat that defines the functionality of the end product. The cheese with added canola oil presented a higher biological value due to atherogenic index of 0.42 compared to 1.60 for cheese produced only of milk fat, thrombogenic index of 0.59 compared to 3.13 for cheese produced only of milk fat and preventive lipid score of 34.89 compared to128.23 for cheese produced only of milk fat.

The fresh cheese with partial replacement of milk fat by canola oil had good sensory properties.

Conclusions. Fresh spreadable cheese with partial replacement of milk fat by canola oil in the ratio (1:1) was characterized by increased healthy characteristics - low levels of atherogenic and prothrombogenic index and preventive lipid score. 


\section{Introduction}

Vegetable oils were used to enhance fatty acids profile of dairy products [1-4]. Enriching the dairy products with omega fatty acids was made mostly by the inclusion of oil seed and vegetable oil in dairy animal diets $[5,6]$. Another possibility was to replace partially or fully the milk fat in dairy products by oils rich in polyunsaturated fatty acids [7, 8]. According to our knowledge, there are insufficient investigations about the enrichment of high fat dairy products with vegetable oils.

Canola oil, in comparison with other vegetable oils, is characterized by the lowest content of saturated fatty acids (less than $10 \mathrm{~g} .100 \mathrm{~g}^{-1}$ ), followed by the walnut and flaxseed oil. It is an excellent source of mono- and polyunsaturated fatty acids, wherein the ratio of omega-6/omega-3 is closest to the optimum [9]. Besides valuable fatty acid composition, canola oil is $[10,11]$. The current trend for the production of health foods requires on the market the production of canola oil with low content of erucic acid, which is associated with certain diseases of the human [12]. This makes reasonable the addition of canola oil in dairy products.

It is appropriate to supplement natural antioxidant when an addition of vegetable oils is used [13]. Sensory profile and valuable antioxidant properties of basil extract, due to contained aromatic components, are appropriate in combination with canola oil in order to reduce oxidation processes in the oil $[14,15]$.

The purpose of this work was to investigate the effect of canola oil and natural basil extract on chemical and sensory properties of fresh spreadable cheese.

\section{Materials and methods}

\section{Raw materials}

Commercially available canola oil (Buldara Ltd., Bulgaria) and fresh natural cream (supplied by United Milk Company AD, Bulgaria) were used.

For the preparation of the emulsions raw cow's milk complying with the requirements of Regulation 853, 2004 from the EU and raw skimmed cow's milk (supplied by United Milk Company AD, Bulgaria) obtained on the day of its adoption were used as dispersible medium.

\section{Other material}

Emulsifier - glyceryl monostearate in amount of $0.1 \mathrm{~g} \mathrm{~cm}^{-3}$, according to data [16] (Cognis with trademark Cutina ${ }^{\circledR}$, Germany), antioxidant - extract from basil ("Extractum" Ltd., Bulgaria) in the amount of $0.003 \mathrm{~cm}^{3} .100 \mathrm{~cm}^{-3}$ with the major components in the chemical composition linalool $10,64 \mathrm{~g} .100 \mathrm{~g}^{-1}$, estragole $46.97 \mathrm{~g} .100 \mathrm{~g} \mathrm{~g}^{-1}$, methyl eugenol 8.94 g.100 g $\mathrm{g}^{-1}, \beta$-bisabolene $3.06 \mathrm{~g} .100 \mathrm{~g}^{-1}$ [17], characterized by sensory profile, suitable for combination with canola oil.

Starter culture with the following composition: Lactococcus lactis subsp. lactis, Lactococcus lactis subsp. cremoris, Streptococcus thermophilus, in the amount of $3 \mathrm{~cm}^{3} .100$ $\mathrm{cm}^{-3}$ ("Lactina" Ltd., Bulgaria).

Rennet - pure chymosin with activity $1: 15000$, in the amount of $5 \mathrm{~cm}^{3} .100 \mathrm{dm}^{-3}$ (Biokom Trendafilov with trademark Daniren $\left.{ }^{\circledR}\right)$.

Oils and cream were stored at $4-6{ }^{\circ} \mathrm{C}$ (Regulation No. 2 of 2017). 


\section{Methods}

Fatty acid composition and total lipid content analyses. The preparation of methyl esters of fatty acids was in accordance with ISO 5509, 2001. The analysis of methyl esters of the fatty acids was carried out by gas chromatography in accordance with ISO 5508:2000. Fatty acid composition of the obtained cheese was determined after extraction of fat by the method of Schmidt-Bonzynsky-Ratzaloff in accordance with ISO 1735|IDF 5:2004.

Sterols analysis. Unsaponifiables were determined by weight after saponification of the lipid fraction and extraction with hexane in accordance with ISO 18609:2000. Identification was confirmed by comparison of retention times with those of a standard mixture of sterols in accordance with ISO 12228:2014.

Tocopherols analysis. Tocopherols were determined directly in the oil by high performance liquid chromatography (HPLC) by Merck-Hitachi (Merck, Darmstadt, Germany) and the tocopherol content was calculated on the base of tocopherol peak areas in the sample vs. tocopherol peak area of the standard tocopherol solution in accordance with ISO 9936:2016.

Emulsion preparation. It was performed by mixing of the two phases - vegetable oil, cream, milk and emulsifier, stirred with a mixer (Polytron ${ }^{\circledR}$ PT45-80) at speed $-150 \mathrm{~s}^{-1}$ during $5 \mathrm{~min}$. The concentrations used were: for emulsifier $0.1 \mathrm{~g} .100 \mathrm{~cm}^{-3}$, for oil phase 4 $\mathrm{cm}^{3} .100 \mathrm{~cm}^{-3}$ canola oil with $4 \mathrm{~cm}^{3} .100 \mathrm{~cm}^{-3}$ cream (1:1). The mixtures were heated to $55-60$ ${ }^{\circ} \mathrm{C}$ in order to complete dissolution of the emulsifier [18].

Fresh cheese preparation with addition of vegetable oil. A flowchart for the production of fresh spreadable cheese and addition of vegetable oil was applied [19]. Qualification of milk $\rightarrow$ Standardization of milk fat to $8 \mathrm{~cm}^{3} .100 \mathrm{~cm}^{-3} \rightarrow\left(4 \mathrm{~cm}^{3} .100 \mathrm{~cm}^{-3}\right.$ canola oil $+4 \mathrm{~cm}^{3} .100 \mathrm{~cm}^{-3}$ milk fat) and addition of antioxidant $0.003 \mathrm{~cm}^{3} .100 \mathrm{~cm}^{-3} \rightarrow$ Heat treatment of milk and addition of emulsifier $\mathrm{t}=55-60{ }^{\circ} \mathrm{C}$ and glyceryl monostearate $(0.1$ g. $\left.100 \mathrm{~cm}^{-3}\right) \rightarrow$ Obtaining of emulsion $\rightarrow$ Pasteurization $\left(88^{\circ} \mathrm{C}\right.$, duration $\left.5 \mathrm{~min}\right) \rightarrow$ Cooling $\left(25^{\circ} \mathrm{C}\right) \rightarrow$ Inoculation $\left(3 \mathrm{~cm}^{3} .100 \mathrm{~cm}^{-3}\right.$ starter culture) $\rightarrow$ Pre-biological ripening (an increase in titratable acidity of $0.018-0.027$ represented as percentage of lactic acid) $\rightarrow$ Addition of rennet $\left(5 \mathrm{~cm}^{3} .100 \mathrm{dm}^{-3}\right) \rightarrow$ Coagulation $(14-16 \mathrm{~h}) \rightarrow$ Cutting of the gel and curd retention in the whey for $30 \mathrm{~min}$ at a temperature of $20-25^{\circ} \mathrm{C} \rightarrow$ Drainage and self-pressing to dry matter approximately $30 \mathrm{~g} .100 \mathrm{~g}^{-1} \rightarrow$ At a temperature of $20-22{ }^{\circ} \mathrm{C}$ for $1-2 \mathrm{~h} \rightarrow$ At a temperature of 4-6 ${ }^{\circ} \mathrm{C}$ overnight $\rightarrow$ Dry salting $\mathrm{NaCl}\left(0.5 \mathrm{~g} .100 \mathrm{~g}^{-1}\right) \rightarrow$ Homogenization of the curd $\rightarrow$ Packaging and cooling.

The data for the chemical composition and biological value of cheese produced only with milk fat were taken from our previous study [19].

Health lipid indices. Qualitative indicators of fat atherogenic index (AI) [20]; Preventive lipid score (PLS) [21]; Thrombogenic index (TI) [22].

Sensory analysis. The sensory evaluation of the fresh cheeses was conducted in accordance with the Bulgarian State Standard 15612-83 and ISO 6654:1991. The evaluation criteria were as follows: taste and flavour -35 points, structure -25 points, consistence -20 points, appearance -10 points, and colour -10 points (maximum overall score -100 points). The results were equated to a 10 point evaluation scale in order to be presented in a spider diagram.

Statistical analysis. The Significance of the differences between the average values was evaluated by Least Significant Difference (LSD) test considering $p<0.05$ as significant [23]. Multiple comparisons were made by LSD method [24]. The results were presented as mean value \pm standard deviation (SD) [25]. 


\section{Results and discussion}

\section{Canola oil analyses}

The results of performed investigations about the fatty acid composition of canola oil are presented in Table 1.

Fatty acid composition of canola oil

Table 1

\begin{tabular}{|c|c|c|}
\hline \multicolumn{2}{|c|}{ Fatty acid } & g.100 $\mathrm{g}^{-1}$ of total fatty acids \\
\hline Lauric acid & C12:0 & $0.06 \pm 0.01^{\mathrm{a}}$ \\
\hline Miristic acid & $\mathrm{C} 14: 0$ & ND \\
\hline Palmitic acid & C16:0 & $5.07 \pm 0.05^{\mathrm{b}}$ \\
\hline Palmitoleic acid & C 16:1 & $0.28 \pm 0.05^{\mathrm{c}}$ \\
\hline Margaric acid & $\mathrm{C} 17: 0$ & $0.06 \pm 0.01^{\mathrm{a}}$ \\
\hline Stearic acid & C18:0 & $0.70 \pm 0.06^{\mathrm{d}}$ \\
\hline Oleic acid & C18:1 & $62.39 \pm 1.15^{\mathrm{e}}$ \\
\hline Linoleic acid & $\mathrm{C} 18: 2$ & $20.06 \pm 1.00^{\mathrm{f}}$ \\
\hline$\alpha$-linolenic acid & $\mathrm{C} 18: 3$ & $9.48 \pm 0.85^{\mathrm{g}}$ \\
\hline Arachidonic acid & C20:0 & $0.55 \pm 0.15^{\mathrm{h}}$ \\
\hline Eicosenoic acid & C20:1 & $1.08 \pm 0.28^{\mathrm{i}}$ \\
\hline Behenic acid & $\mathrm{C} 22: 0$ & $0.27 \pm 0.09^{j}$ \\
\hline Erucic acid & C22:1 & ND \\
\hline
\end{tabular}

The data showed that 13 fatty acids were identified which presented $99.97 \mathrm{~g} .100 \mathrm{~g}^{-1}$ of total fatty acids. The oleic $62.39 \mathrm{~g} .100 \mathrm{~g}^{-1}$ of total fatty acids and linoleic $20.06 \mathrm{~g} .100 \mathrm{~g}^{-1}$ of total fatty acids were prevailing.

Figure 1 presents the fatty acids distribution in canola oil.

The results showed that the canola oil was characterized by a high content of unsaturated fatty acid content above $93 \mathrm{~g} .100 \mathrm{~g}^{-1}$ of the total content and a very good ratio of omega$6 /$ omega-3 - 2/1. The data on fatty acid composition were similar to those obtained by other research teams, for varieties with low erucic acid (C22:1), which emphasizes its healthfulness [12]. Essential fatty acids (C18:2 and C18:3) laid in high amounts on the total content of unsaturated fatty acid content above $30 \mathrm{~g} .100 \mathrm{~g}^{-1}$. These indicators determined the health characteristics of canola oil and defined it as a vegetable oil with high quality fatty acid profile.

The data showed that canola oil had a very low content of saturated fatty acids, and this indicator was superior to other vegetable oils such as walnut, flaxseed, etc. [26, 27]. The high amount of mono unsaturated fatty acids was similar to that of olive oil and helps the right functioning of various physiological systems in the human body. The amount of omega-3 fatty acids (C18:3), was increased in comparison to other vegetable oils - olive, corn, sunflower and others [19]. 

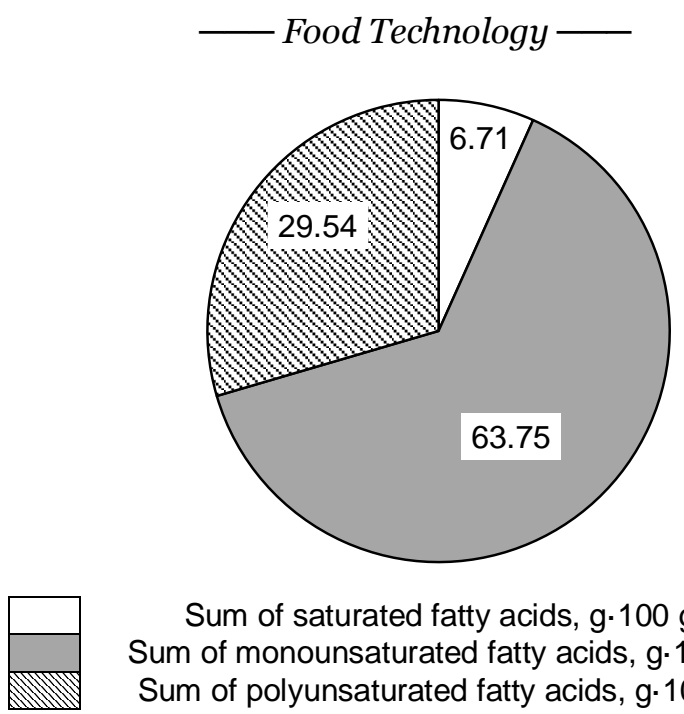

Sum of saturated fatty acids, $\mathrm{g} \cdot 100 \mathrm{~g}^{-1}$

Sum of monounsaturated fatty acids, $\mathrm{g} \cdot 100 \mathrm{~g}^{-1}$

Sum of polyunsaturated fatty acids, $\mathrm{g} \cdot 100 \mathrm{~g}^{-1}$

Figure 1. Distribution of the fatty acid groups in canola oil

The tendency of oils to oxidation was determined by the content of polyunsaturated fatty acids. Vegetable oils contained different amounts of natural antioxidants - tocopherols $(\alpha, \beta, \gamma, \delta)$, which limited the oxidation processes. An important indicator of the healthy nature of canola oil was phytosterol content (brassicasterol, campesterol, $\beta$-sitosterol, $\Delta 5$ avenasterol, $\Delta 7$-avenasterol) [28]. Therefore, the content of tocopherols and phytosterols in canola oil was investigated. The data obtained are presented in Table 2 . The data showed that canola oil was characterized by a high content of $\alpha$ and $\gamma$-tocopherols, an important indicator of the antioxidant properties of the vegetable oils [29].

The results showed that canola oil was characterized by a high content of phytosterols, which, according to several studies lower the cholesterol and the level of LDL cholesterol in the blood [30]. The total content in the oil was found to be $0.7 \mathrm{~g} .100 \mathrm{~g}^{-1}$. The individual sterol composition is presented in Table 2. $\beta$-Sitosterol $\left(54.7 \mathrm{~g} .100 \mathrm{~g}^{-1}\right)$ and campesterol (35.3 g. $100 \mathrm{~g}^{-1}$ ) predominated in the sterol fraction.

Tocopherols are a class of organic chemical compounds, many of them have vitamin $\mathrm{E}$ activity. The total content of tocopherols in the lipid fraction was comparatively higher -315 mg. $\mathrm{kg}^{-1}$. The tocopherol composition is presented in Table 2. The $\gamma$-tocopherol predominated in the oil, followed by $\alpha$-tocopherol. The oil with higher content of $\alpha$ and $\gamma$-tocopherol proved superior to a number of common food oils [28].

Tocopherol and phytosterol content in canola oil

Table 2

\begin{tabular}{|c|c|c|c|c|c|c|}
\hline \multirow{4}{*}{$\begin{array}{c}\text { Total, mg } \\
\mathbf{k g}^{-1}\end{array}$} & \multicolumn{5}{|c|}{ Tocopherols content, \% of tocopherol content } \\
\cline { 2 - 7 } $\begin{array}{c}\text { Canola } \\
\text { oil }\end{array}$ & \begin{tabular}{c}
$\alpha$ \\
\cline { 2 - 6 }
\end{tabular} & $\begin{array}{c}\text { Total, } \mathbf{g} \\
\mathbf{1 0 0 ~}^{-1}\end{array}$ & \multicolumn{5}{|c|}{ Phytosterols content, \% of phytosterol content } \\
\cline { 2 - 7 } & Brassicasterol & Campesterol & $\beta$-sitosterol & $\begin{array}{c}\Delta 5 \\
\text { avenasterol }\end{array}$ & $\begin{array}{c}\Delta 7 \\
\text { avenasterol }\end{array}$ \\
\cline { 2 - 7 } & $0.7 \pm 0.0$ & $9.6 \pm 0.2^{\mathrm{a}}$ & $35.3 \pm 0.5^{\mathrm{b}}$ & $54.7 \pm 0.5^{\mathrm{c}}$ & $0.2 \pm 0.1^{\mathrm{d}}$ & $0.1 \pm 0.0^{\mathrm{e}}$ \\
\hline
\end{tabular}

a-e Means in the same row with different letters show significant differences $(p<0.05) ;{ }^{*}$ Values are expressed as mean \pm Standard deviation $(n=3)$ 


\section{Fresh cheese analyses}

An important characteristic of the end product is its biological and functional value. Healthiness of cheese with canola oil was determined on the basis of the content of fatty acids and indicators characterizing the wholesomeness of fats, presented in Table 3 and Table 4.

The data showed that the cheese with partial replacement of milk fat by canola oil was characterized by a reduced content of saturated fatty acids which have negative effects on human health $-35.02 \mathrm{~g} .100 \mathrm{~g}^{-1}$ compared to $68.33 \mathrm{~g} .100 \mathrm{~g}^{-1}$ in cheese by classical technology containing only milk fat [19].

The product contained a large part of the short-chain fatty acids, typical for milk fat that defines the functionality of the end product [31,32].

Figure 2 presents the fatty acids distribution in in cheese with canola oil.
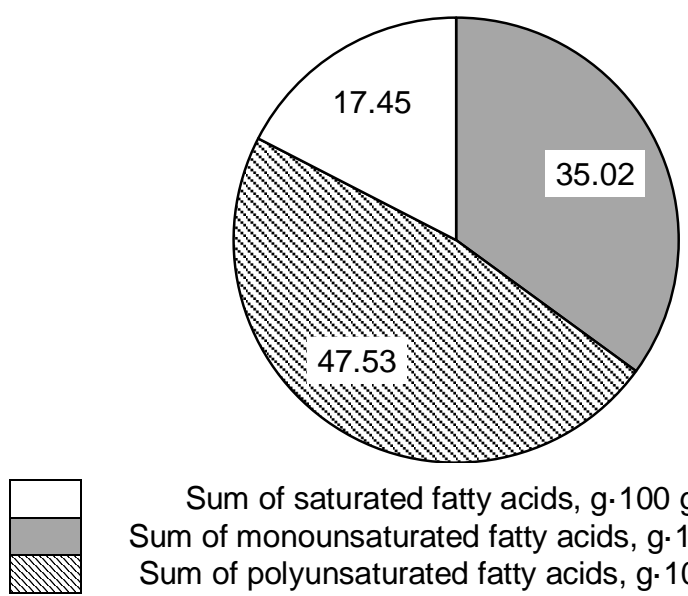

Sum of saturated fatty acids, $\mathrm{g} \cdot 100 \mathrm{~g}^{-1}$

Sum of monounsaturated fatty acids, $\mathrm{g} \cdot 100 \mathrm{~g}^{-1}$

Sum of polyunsaturated fatty acids, $g \cdot 100 \mathrm{~g}^{-1}$

Figure 2. Distribution of the fatty acid groups in cheese with canola oil

The cheese with partial replacement of milk fat by canola oil was characterized by an increased content of unsaturated fatty acids in comparison to cheese, which contains only milk fat [19]. Increased wholesomeness of the end product was determined by the content of oleic acid (C18:1), linolenic acid (C18:3) and linoleic acid (C18:2). Our results were comparable with the reported fatty acid composition studies of dairy products enriched with canola oil [6].

Table 4 presents the evaluation of the biological value of the cheese determined by qualitative indicators of fat values - atherogenic index 0.42 compared to 1.60 for cheese produced only with milk fat, thrombogenic index 0.59 compared to 3.13 for cheese produced only with milk fat and preventive lipid score 34.89 compared to 128.23 for cheese produced only with milk fat [19]. These indicators in the control sample were three to four times higher compared to the cheese with canola oil, which shows higher biological value of the product with vegetable oil. It represents a healthier version of traditional fresh spreadable cheese produced only of milk fat. A similar tendency was observed by other authors [33-35]. 
Fatty acid composition of cheese with canola oil

Table 3

\begin{tabular}{|c|c|c|}
\hline \multicolumn{2}{|l|}{ Fatty acid } & g $100 . g^{-1}$ of total fatty acids \\
\hline Caproic acid & C6:0 & $0.09 \pm 0.00^{\mathrm{a}}$ \\
\hline Caprilic acid & C8:0 & $0.96 \pm 0.10^{b}$ \\
\hline Capric acid & C10:0 & $1.67 \pm 0.15^{\mathrm{c}}$ \\
\hline Lauric acid & C12:0 & $5.70 \pm 0.85^{\mathrm{d}}$ \\
\hline Miristic acid & C14:0 & $0.64 \pm 0.15^{\mathrm{e}}$ \\
\hline Palmitic acid & C16:0 & $19.18 \pm 1.12^{\mathrm{f}}$ \\
\hline Palmitoleic acid & C16:1 & $1.16 \pm 0.15^{\mathrm{g}}$ \\
\hline Margaric acid & C17:0 & $0.37 \pm 0.09^{\mathrm{h}}$ \\
\hline Margarinoleic acid & C17:1 & $0.20 \pm 0.05^{\mathrm{i}}$ \\
\hline Stearic acid & C18:0 & $6.41 \pm 0.95^{\mathrm{j}}$ \\
\hline Oleic acid & C18:1 & $46.17 \pm 2.14^{\mathrm{k}}$ \\
\hline Linoleic acid & C18:2 & $12.77 \pm 1.00^{1}$ \\
\hline$\alpha$-linolenic acid & C18:3 & $4.68 \pm 0.88^{\mathrm{m}}$ \\
\hline
\end{tabular}

Health lipid indices of cheese with canola oil

Table 4

\begin{tabular}{|c|c|}
\hline Health lipid indices & g. $100 \mathrm{~g}^{-1}$ of total fatty acids* \\
\hline Atherogenic index & 0.42 \\
\hline Trombogenic index & 0.59 \\
\hline Preventive lipid score & 34.89 \\
\hline Total cheese lipid content & 20.70 \\
\hline
\end{tabular}

*Values are expressed on the basis of mean fatty acid content

An important characteristic of the end product is its sensory profile. Figure 3 presents the sensory characteristics of fresh cheese with partial replacement of milk fat by canola oil and antioxidant of basil extract. The sensory profile showed that fresh cheese with partial replacement of milk fat by canola oil had good sensory characteristics. Some variation in colour was established due to the specific sensory profile of canola oil. The values for the indicators of taste and aroma remained relatively high, indicating that canola oil can be successfully used for the partial replacement of milk fat. The overall assessment of sensory indicators was 47.5 of maximum 50 points. Our results complied with the results obtained by other authors [36, 37]. 


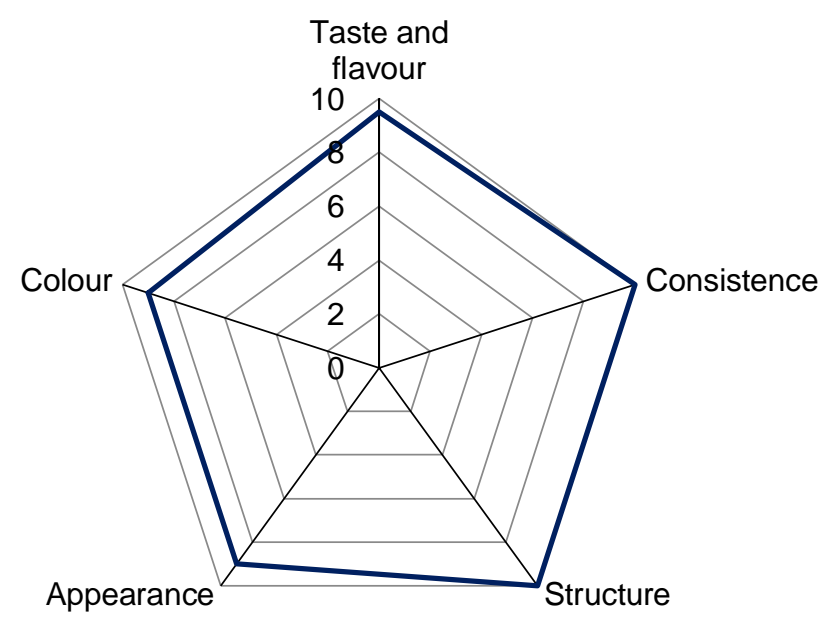

Figure 3. Sensory profile of the cheese enriched with canola oil

\section{Conclusions}

The fresh cheese with partial replacement of milk fat by canola oil and the addition of natural antioxidant of basil extract was characterized by improved fatty acid profile, and a significant higher content of essential polyunsaturated fatty acids.

The cheese with partial replacement of milk fat by canola oil was a very good source of tocopherols and phytosterols, which increased its healthy characteristics.

Qualitative indicators of fat - atherogenic and thrombogenic index and preventive lipid score defined the product as a healthy version of the classic fresh high fat spreadable cheese containing only milk fat and reduces the risk of various diseases associated with the consumption of animal fats.

\section{References}

1. Ardabilchi Marand M., Amjadi S., Ardabilchi Marand M., Roufegarinejad L., Jafari S.M (2020), Fortification of yogurt with flaxseed powder and evaluation of its fatty acid profile, physicochemical, antioxidant, and sensory properties, Powder Technology, 359, pp. 76-84.

2. Bakry A.M., Chen Y., Liang L. (2019), Developing mint yogurt enriched with omega-3 oil: Physicochemical, microbiological, rheological, and sensorial characteristics, Journal of Food Processing and Preservation, 43(12), pp. 14287.

3. Goyal A., Sharma V., Sihag M.K., Singh A.K., Arora S., Sabikhi L. (2016), Fortification of dahi (Indian yoghurt) with omega-3 fatty acids using microencapsulated flaxseed oil microcapsules, Journal of Food Science and Technology, 53(5), pp. 2422-2433. 


\section{— Food Technology —}

4. Ganesan B., Brothersen C., McMahon D.J. (2014), Fortification of Foods with Omega-3 Polyunsaturated Fatty Acids, Critical Reviews in Food Science and Nutrition, 54 (1), pp. 98 114.

5. Goiri I. Zubiria I., Benhissi H., Atxaerandio R., Ruiz R., Mandaluniz N., Garcia-Rodriguez A (2019), Use of cold-pressed sunflower cake in the concentrate as a low-input local strategy to modify the milk fatty acid profile of dairy cows, Animals, 9(10), pp. 803.

6. Nguyen Q.V., Malau-Aduli B.S., Cavalieri J., Malau-Aduli A.E.O., Nichols P.D. (2019), Enhancing omega-3 long-chain polyunsaturated fatty acid content of dairy-derived foods for human consumption, Nutrients, 11(4), pp. 743.

7. Dal Bello B., Torri L., Piochi M., Bertolino M., Zeppa G. (2017), Fresh cheese as a vehicle for polyunsaturated fatty acids integration: effect on physico-chemical, microbiological and sensory characteristics, International Journal of Food Sciences and Nutrition, 68(7), pp. 800 810.

8. Soliman T.N., Farrag A.F., Zahran H.A.-H., El-Salam M.E.-H.A. (2019), Preparation and properties nano-encapsulated wheat germ oil and its use in the manufacture of functional labneh cheese, Pakistan Journal of Biological Sciences, 22(7), pp. 318-326.

9. Daun J. K., Michael Eskin N.A., Hickling D. (2011), Canola: Chemistry, Production, Processing, and Utilization, Elsevier Science, pp. 432.

10. Ghazani S.M., Marangoni A.G. (2016), Nutrition and food grains in Encyclopedia of Food Grains, Academic Press.

11. Savva C., Kafatos A. (2016), Encyclopedia of Food and Health, Academic Press.

12. Lin L., Allemekinders H., Dansby A., Campbell L., Durance-Tod S., Berger A., Jones P. (2013), Evidence of health benefits of canola oil, Nutrition Review, 71(6), pp. 370-385.

13. Taghvaei M., Jafari C. M. (2015), Application and stability of natural antioxidants in edible oils in order to substitute synthetic additives, Journal of Food Science and Technology, 52(3), pp. 1272-1282.

14. Juliani H., Simon J. (2002), Antioxidant Activity of Basil. Trends in new crops and new uses, J. Janick and A. Whipkey, ASHS Press, Alexandria, VA.

15. El-Sayed S. M., Youssef A. M. (2019), Potential application of herbs and spices and their effects in functional dairy products, Heliyon, 5(6), pp. 01989.

16. Hasenhuettl G., Hartel R. (2008), Food emulsifiers and their applications, Springer, Berlin.

17. Nenov N., Girova V., Iliev I., Stoilova I., Stoyanova A. (2014), Low temperature extraction of essential oil bearing plants by liquefied cases. 20. Basil (Ocimum basilicum L.), Proceedings of International scientific conference Voronej, 140.

18. Vlaseva R., Ivanova M., Petkova N., Denev P., Stoyanova A., Schreiner, M. (2014), Obtaining stable food emulsions between milk and corn oil, Bulgarian Journal of Agricultural Science, 20(5), pp. 1085-1089.

19. Ivanova M. (2016), Obtention de fromage à la composition régulée de la matière grasse, Saarbrucken, Germany: Editions universitaires européennes, (Chapter 3.3.2) (Fr).

20. Ulbritch T., Southgate D. (1991), Coronary heart disease: seven dietary factors, Lancet, 338, pp. 985-992.

21. Richard J., Charbonnier A. (1994), Description d'un score lipidique des aliments, Cahiers de nutrition et de diététique, 4, pp. 234-240.

22. Senso L., Suarez M., Ruiz-Cara T., Garcia-Gallego M. (2007), On the possible effects of harvesting season and chilled storage on the fatty acid profile of the fillet of farmed gilthead sea bream (Sparus aurata), Food Chemistry, 101(1), pp. 298-307.

23. Dilchva M., Kinova V. (2008), Modeling and optimization of technological processes, UFT, Plovdiv, pp. 14-28.

24. Donchev D., Dilcheva M, Kinova V. (2002), A Practical Guide to Statistical Data Analysis, ABT Spectrum, Plovdiv, pp. 110-118. 


\section{Food Technology —}

25. Petrova N., (2002), Theory of probability and statistics, HIFFI Academic Publishing House, Plovdiv, pp. 86-97.

26. Jahanban-Esfahlan A., Ostadrahimi A., Tabibiazar M., Amarowicz R. (2019), A Comprehensive Review on the Chemical Constituents and Functional Uses of Walnut (Juglans spp.) Husk, International Journal of Molecular Science, 20(16), pp. 3920.

27. Goyal A., Sharma V., Upadhyay N., Gill S., Sihag M. (2014), Flax and flaxseed oil: an ancient medicine \& modern functional food, Journal of Food Science and Technology, 51(9), pp. 1633-1653.

28. Popov A., Ilinov P. (1986), Chemistry of lipids. Nauka i Iskustvo, Sofia (Bg).

29. Schwartz H., Ollilainen V., Piironen V., Lampi A. (2008), Tocopherol, tocotrienol and plant sterol contents of vegetable oils and industrial fats, Journal of Food Composition and Analysis, 21(2), pp. 152-161.

30. Lecerf J., Bard J., Girardet J, Fumeron F., Paillard F., Vergès B. (2014), Phytostérols, phytostanols, et risque cardiovasculaire, Médecine des Maladies Métaboliques, 8(5), pp. 483488.

31. Besten G.D., Eunen K.V., Groen A.K., Venema K., Reijngoud D.J., Bakker B.M. (2013), The role of short-chain fatty acids in the interplay between diet, gut microbiota, and host energy metabolism, Journal of Lipid Research, 54(9), pp. 2325-2340.

32. Niccolai E., Baldi S., Ricci F., Russo E., Nannini G., Menicatti M., Poli G., Taddei A., Bartolucci G., Calabrò A.S., Stingo F.C., Amedei A. (2019), Evaluation and comparison of short chain fatty acids composition in gut diseases, World Journal of Gastroenterology, 25(36), pp. 5543-5558.

33. Xu J., Zhou X., Deng Q., Huang Q., Yang J., Huang F. (2011), Rapeseed oil fortified with micronutrients reduces atherosclerosis risk factors in rats fed a high-fat diet, Lipids in Health and Disease, 10, pp. 96.

34. Abdelhamid A.S., Martin N., Bridges C., Brainard J.S., Wang X., Brown T.J., Hanson S., Jimoh O.F., Ajabnoor S.M., Deane K., Song F., Hooper L. (2018), Polyunsaturated fatty acids for the primary and secondary prevention of cardiovascular disease, Cochrane Database of Systematic Reviews, 7, CD012345.

35. Hooper L., Al-Khudairy L., Abdelhamid A.S, Rees K., Brainard J.S, Brown T.J., Ajabnoor S.M., O'Brien A.T., Winstanley L.E., Donaldson D.H., Song F., Deane K. (2018), Omega-6 fats for the primary and secondary prevention of cardiovascular disease, Cochrane Database of Systematic Reviews, 11, CD011094.

36. Farmani J., Edalatkhah M., Motamedzadegan A., Mardani M. (2016), Production of set yoghurt analogue through replacement of milk fat with canola and sesame oil, International Journal of Dairy Technology, 69(3), pp. 433-440.

37. Dal Bello B., Torri L., Piochi M., Zeppa G. (2015), Healthy yogurt fortified with n-3 fatty acids from vegetable sources, Journal of Dairy Science, 98(12), pp. 8375-8385. 